\section{CPAP Devices for Emergency Prehospital Use: Looking Inside of It}

\section{To the Editor:}

Prehospital use of CPAP reduces the mortality and intubation rate for patients with acute respiratory failure especially due to acute cardiogenic pulmonary edema. ${ }^{1}$ Although it is considered in guidelines, the need for additional trained health workers, special equipment, and clinical evidence for effectiveness and cost-effectiveness limits widespread use. ${ }^{1,2}$ The Boussignac CPAP facial mask is a compact CPAP system that has been used frequently in emergency services. ${ }^{3,4}$ This system is simple, safe, and portable and requires only an oxygen source, so it can be used easily by paramedical personnel. Also, Boussignac CPAP has been shown to be effective for acute cardiogenic pulmonary edema in the emergency department. ${ }^{3,4}$

We read with great interest the RESPIRATORY CARE article by Brusasco et al ${ }^{5}$ entitled "CPAP devices for emergency prehospital use: a bench study." The study evaluated and compared on a bench model the performance of 3 orofacial mask devices (Ventumask, EasyVent, and Boussignac CPAP system) and 2 helmets (Ventukit and EVE Coulisse). The efficiency of the devices was compared based on oxygen flow needed to generate a minimum air flow of $60 \mathrm{~L} / \mathrm{min}$ at each CPAP setting. The authors found that only the EasyVent and EVE Coulisse achieved the required minimum level of air flow output needed to ensure an effective therapy under all CPAP conditions. This study definitely requires attention, since it provides valuable information for clinicians and prehospital medical staff about specific device performance features to optimize effective application of CPAP in prehospital and emergency settings. However, we think that there are some issues that deserve comment.

First, information about or comparisons of the cost of these devices were not given. It is essential to demonstrate the cost-effectiveness of prehospital CPAP to ensure its widespread clinical use. Cost-effective treatment strategies for acute cardiogenic pulmonary edema are needed to avoid the need for intubation and mechanical ventilation. Hubble et al $^{6}$ did a study to estimate costeffectiveness of CPAP in managing prehospital acute cardiogenic pulmonary edema in an urban medical emergency system. They calculated and compared prehospital CPAP costs with hospitalization costs, including ICU stay. CPAP equipment constitutes the largest portion of calculated prehospital costs. Based on the theoretical cost-effectiveness analysis, they concluded that CPAP is a cost-effective prehospital treatment. The authors in this study obviously gave technical information and bench test results for these devices. However, we think that brief information about and comparison of the cost should be given, although this is not included in the aim of the study.

Second, we think that bench test effectiveness and efficacy of these devices cannot be adapted to clinical events. Not only the known patient-dependent variabilities of noninvasive ventilation but also prehospital application with its own difficulties and factors should be considered. The authors simulated tidal volume of $500 \mathrm{~mL}$, inspiratory time of $0.8 \mathrm{~s}$, expiratory time of $1.6 \mathrm{~s}$, and breathing frequency of 25 breaths/min on each device to test the in vitro circuit. Nevertheless, given the diversity of prehospital clinical scenarios of respiratory failure, these parameters cannot simulate all patients with acute respiratory failure in the prehospital setting. Also, to achieve clinical success with prehospital use of these devices, paramedic training is necessary. The lack of training also may interfere with the effectiveness of the devices. ${ }^{7}$

This study provides valuable and useful information about technical effectiveness of 5 different commercially available mask devices developed for CPAP therapy in the prehospital setting. However, it does not reflect field- and patient-based differences that affect success. We recommend large randomized clinical studies for devices available for prehospital CPAP treatment.

Cüneyt Salturk MD

Department of Intensive Care Unit Sureyyapasa Chest Disease and Research

Hospital

Istanbul, Turkey

Antonio M Esquinas MD PhD Intensive Care and Non-Invasive Ventilatory Unit

Hospital Morales Meseguer Murcia, Spain

The authors have disclosed no conflicts of interest.

DOI: $10.4187 /$ respcare. 04733

\section{REFERENCES}

1. Goodacre S, Stevens JW, Pandor A, Poku E, Ren S, Cantrell A, et al. Prehospital noninvasive ventilation for acute respiratory failure: systematic review, network metaanalysis, and individual patient data metaanalysis. Acad Emerg Med 2014;21(9):960970.

2. Daily JC, Wang HE. Noninvasive positive pressure ventilation: resource document for the National Association of EMS Physicians position statement. Prehosp Emerg Care 2011;15(3):432-438.

3. Moritz F, Benichou J, Vanheste M, Richard JC, Line S, Hellot MF, et al. Boussignac continuous positive airway pressure device in the emergency care of acute cardiogenic pulmonary oedema: a randomized pilot study. Eur J Emerg Med 2003; 10(3):204-208

4. Leman P, Greene S, Whelan K, Legassick T. Simple lightweight disposable continuous positive airways pressure mask to effectively treat acute pulmonary oedema: randomized controlled trial. Emerg Med Australas 2005;17(3):224-230.

5. Brusasco C, Corradi F, De Ferrari A, Ball L, Kacmarek RM, Pelosi P. CPAP devices for emergency prehospital use: a bench study. Respir Care 2015;60(12):1777-1785.

6. Hubble MW, Richards ME, Wilfong DA. Estimates of cost-effectiveness of prehospital continuous positive airway pressure in the management of acute pulmonary edema. Prehosp Emerg Care 2008;12(3): 277-285.

7. Knox N, Chinwe O, Themba N, Joseph F, Hormoz A. Relationship between intubation rate and continuous positive airway pressure therapy in the prehospital setting. World J Emerg Med 2015;6(1):60-66.

\section{CPAP Devices for Emergency Prehospital Use: Looking Inside of It-Reply}

In reply:

We thank Drs Salturk and Esquinas for their interest and comments on our paper entitled "CPAP devices for emergency prehospital use: a bench study." ${ }^{1}$ We absolutely agree with them that this study only represents a technical basis for clinical studies, which are necessary to make recommendations for clinical use of CPAP devices under different pathophysiological conditions. We also agree that economic aspects are important, but this was beyond the scope of our bench study because the cost of devices may differ depending on the country and agreements between local health authorities 